\title{
Dynamic Optimization of Energy Supply Systems with Modelica Models
}

\author{
CHR. Hoffmann \\ H. Puta \\ Technische Universität Ilmenau \\ P.O. Box 1005 65, 98694 Ilmenau, Germany
}

\begin{abstract}
The paper describes a design tool for decentralised energy supply by preferable use of renewable energy. The powerful modelling language Modelica has been used to develop a model library for input data generation and/or predicting and modelling the main parts of the energy supply system for the simulation tool Dymola. An optimal control design using the well suited Dymola model in connection with Matlab [21] is performed with the solver HQP [15]. Application to a solar heating supply system with two storages demonstrates the effect of minimizing the use of additional heating and the realization by a model predictive control strategy.
\end{abstract}

\section{Introduction}

To build a moor it needs about 50000 years, the youngest brown coal dates from 65 million years ago, about 1850 the first coal (also oil and a bit later gas) was excavated and newest estimations predict that coal, oil and gas from soil may be spent in about 2250, completely. That means human activity has consumed all the natural resources developed in millions of years within a delta impulse on time scale i.e. within about 400 years!

Realizing these facts it is high time that renewable energy sources become more and more important, mainly due to the shortage of fossil fuels, which is well known. Fortunately, we still can dispose over mixed energy supply, with great challenges arising for planning and control of heat supply systems, if these systems also work with different renewable energy sources (earth heat, solar radiation, exhaust air heat from building), which lead to control problems with a higher rank of complexity. The main goal of these control strategies (taking into account the weather of the past and predictions of energy requirement in the future) is the re- duction of operational cost as well as an increase in the rate of return for the investment.

The paper describes the simulation of a heat supply system by means of object-oriented modelling with Dymola/Modelica. The final aim of such a simulation is to develop a model predictive control strategy on the basis of the proposed object-oriented model in Dymola/Modelica. To develop such a control strategy it is necessary to gain knowledge about the heat demand of buildings and the power usage of its different components. The use of Computer Aided Engineering (CAE) can lead to a further reduction of development costs. A Dymola library named RECOMB has been created with the purpose of modelling and simulation of such heat supply systems. The name RECOMB [16] stands for Renewable Energy Components módelling and optiMisation of

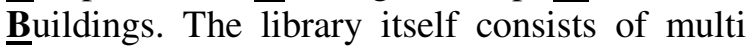
sub-libraries and following sub-libraries of crucial importance:

- Weather

- Predict

- HESys

- Buildings

The components and the resulting models for the thermodynamic models of the sub-library HESys were validated by comparing them with existing simulation software [11], [12], while the building models were validated with help of German guidelines [9] as well as with other simulation software [8],[10]. Fig. 1 show the structures of the library RECOMB. 


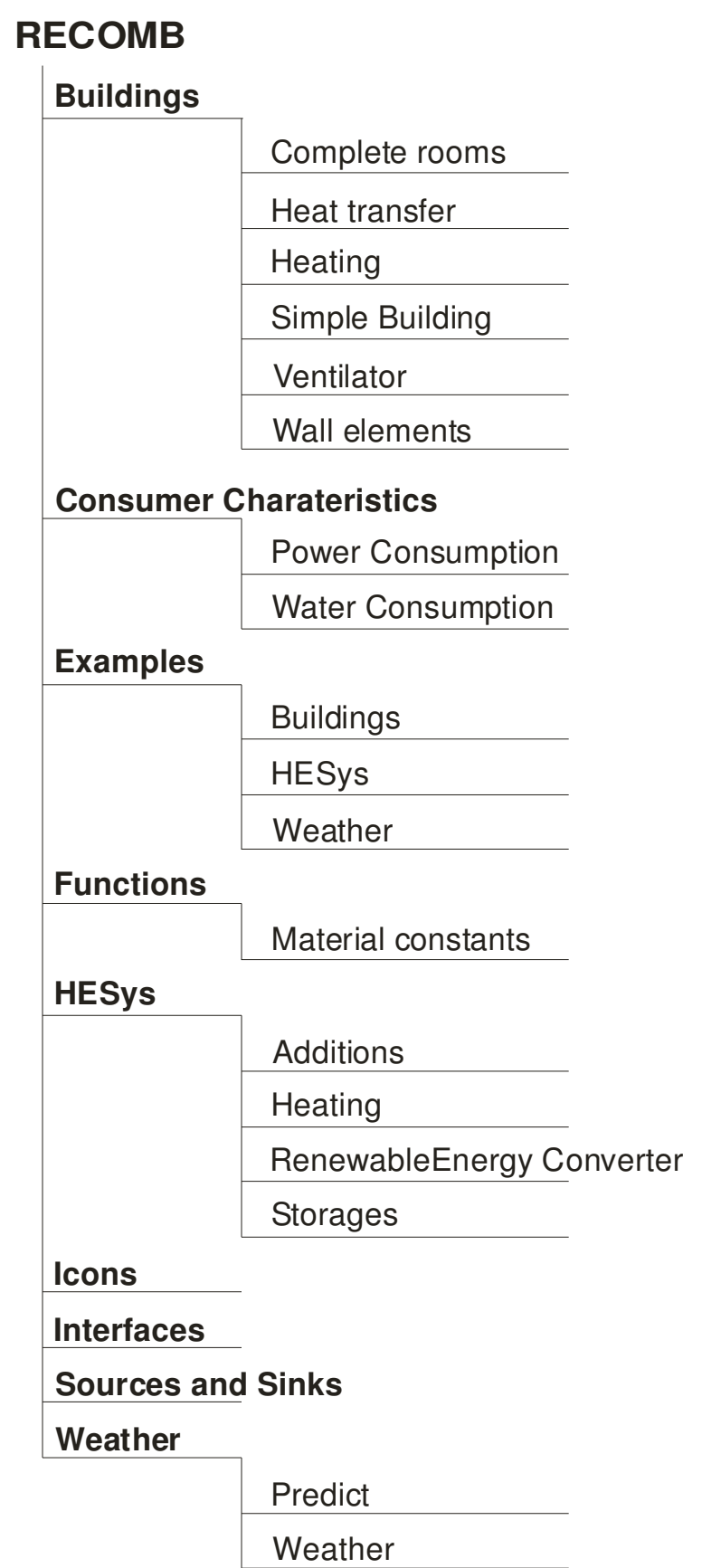

Fig. 1: Structure chart of RECOMB

This library constitutes the basic of the dynamic optimization by HQP und discrete dynamic programming by Matlab. It uses the advantage of the object-oriented modeling over the illustration the material flows and information flows.

\section{Optimization}

In this article three different possibilities the dynamic optimization using the Dymola/Modelica model are shown:

1. Offline optimization by HQP and Simulink S-function interface

2. Model predictive control (MPC) by HQP and Simulink S-function interface

3. Discrete dynamic programming (DDP) by Matlab coupled with Dymola models via Simulink Sfunction interface

The main goals of the different optimization possibilities are the maximization the renewable energy part to the supply of buildings and the analysis of the performance of the methods. The general continuous-time optimization problem to be solved is:

$I(\mathbf{x}(t), \mathbf{u}(t))=\vartheta\left[\mathbf{x}\left(t_{f}\right)\right]+\int_{t_{0}}^{t_{f}} \mathbf{\Phi}[\mathbf{x}(t), \mathbf{u}(t), t] d t \rightarrow \min _{\mathbf{u}(t)}$

with the constrains:

$\mathbf{x}\left(t_{0}\right)=\mathbf{x}_{\mathbf{0}}$ (intial states)

$\mathbf{g}\left[\mathbf{x}\left(t_{f}\right)\right]=0$ (final state constraints)

$\mathbf{f}[\mathbf{x}(t), \mathbf{u}(t), t]=0 \quad \forall t \in\left[t_{0}, t_{f}\right]$ (equality constraints)

$\mathbf{h}[\mathbf{x}(t), \mathbf{u}(t), t] \leq 0 \quad \forall t \in\left[t_{0}, t_{f}\right]$ (inequality constraints)

The form of this criterion is referred to as Bolza functional with Mayer term (end state evaluation) and Lagrange term (evaluation of the energy).

A first order differential equation system describes the system to be optimized in the form: $\dot{\mathbf{x}}(t)=\mathbf{f}[\mathbf{x}(t), \mathbf{u}(t), t] t \in\left[t_{0}, t_{f}\right]$

The vector $\mathbf{x}(t)$ describes the state vector and the vector $\mathbf{u}(t)$ the control vector.

The optimization tool HQP is a numerical optimal solver and before this tool can be used for the solution of the optimization problem, the problem must be discretized. The exactly discretized optimization problem is shown in subsection 3 . The simple form of the general nonlinear optimization problem is: 
$\mathbf{x}=\left(\begin{array}{c}\mathbf{x}^{0} \\ \mathbf{u}^{0} \\ \mathbf{u}^{1} \\ \vdots \\ \mathbf{u}^{\mathrm{K}-1}\end{array}\right)$

$I(\mathbf{x}) \rightarrow \min _{\mathbf{x}}$ with $\mathbf{c}_{\text {ineq }}(\mathbf{x}) \leq 0($ in -

equality constraints) and $\mathbf{c}_{e q}(\mathbf{x})=0$ (equality constraints)

\section{Offline optimization by HQP and Simulink s- function interface}

For dynamic optimization using the Dymola Modelica model the following criterion has to be maximized:

$$
I(u)=\int_{t_{0}}^{t_{f}}\left[a_{1} Q_{\text {cum }}(t)-a_{2} E_{F}(t)+a_{3} Q_{H P}(t)\right] d t
$$

The weighting factors $a_{1}$ to $a_{3}$ allow to adjust proper priorities, if the use of fossil energy $\left(E_{F}\right)$ should be minimized and renewable energy $\left(\mathrm{Q}_{\text {cum }}\right.$ and $\left.\mathrm{Q}_{\mathrm{HP}}\right)$ should be preferably used, where the index "cum" stands for cumulated solar energy and "HP" for heat pump. Because the powerful optimization tool HQP [15] had worked very well together with Matlab, the Dymola/Modelica model of the system was transferred to Matlab/Simulink. Fig. 2 shows the steps of optimization.

\section{Procreation of a Modelica model}

\section{Transformation into Simulink model}

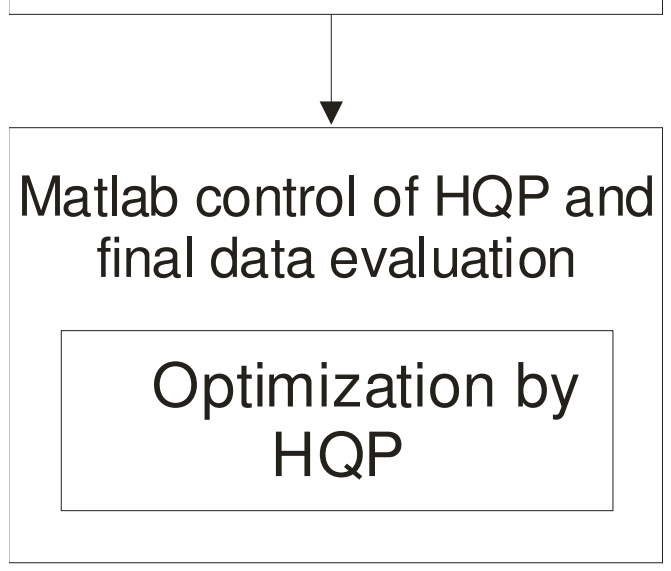

Fig. 2: Steps of optimization

The model of a two storage solar heating system was used to demonstrate how optimization works and to make sure the load strategy for these two storages will provide minimal additional heating.

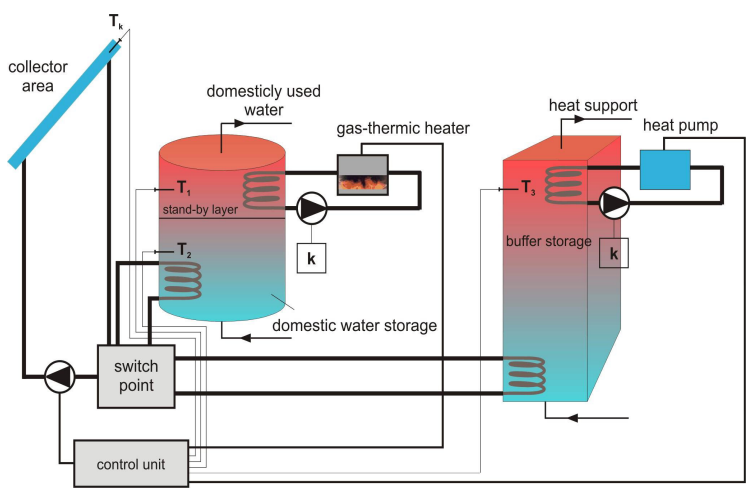

Fig. 3: Two storage heating system 


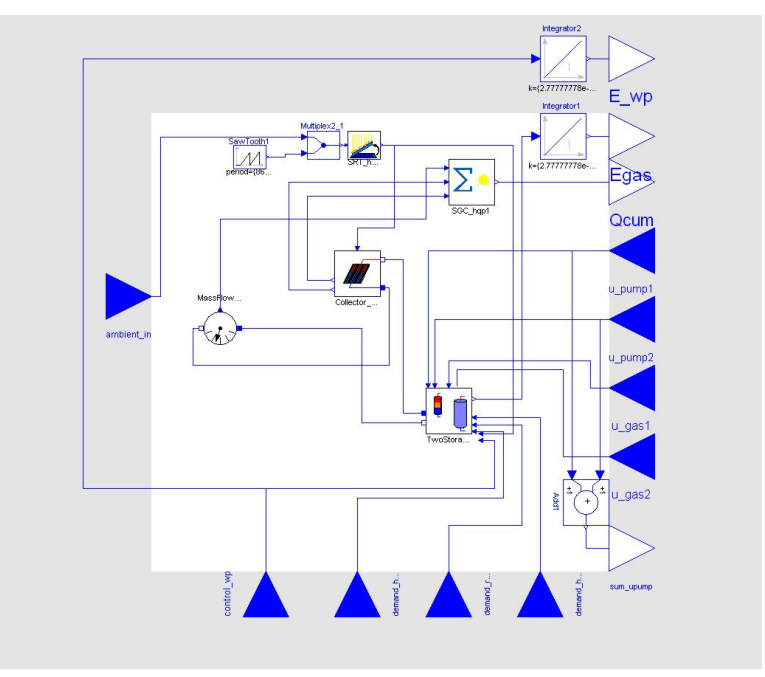

Fig. 4: Modelica model from two storage heating system

Fig. 3 shows this plant with the following data:

- collector area: $5 \mathrm{~m}^{2}$

- short term storage with a stand-by layer of 1351

and a rest part of 1651 , i.e. together 3001 of content.

- long term (buffer) storage of 10001

- heat pump: $5 \mathrm{KW}$

- gas burner: 10KW.

Fig. 4 shows the two storage heating system as a Dymola/Modelica model with different Inports und Outports.

For safety the circulating pumps for heat pump and gas burner are always working, even when both devices are not in action, indicated by $\mathrm{k}$. The aim of optimization is to calculate the load dependent control strategies, i.e. for the switch between the two storages, the heat pump and the gas burner. Constraints have to be taken into account such as: minimum temperature between short term storage and long term storage of $333 \mathrm{~K}$, control constraints with respect to mass flow of gas, electrical power of the heat pump (5 KW) and the mass flow of the variable pump for storages $(0.139 \mathrm{~kg} / \mathrm{s})$. By weighting factors $a_{1}$ to $a_{3}$ in the cost functional regenerative energy use may be preferably controlled. For the example (Fig. 4) the following factors were used:

$a_{1}=700, a_{2}=100, a_{3}=200$. By these values $a$ better scaling of the optimization problem is achieved. Figs. 6 - 10 show that the given constraints can be met.

For online application a model predictive control scheme was developed (Fig. 10), tested with the one storage and the two storage system. The results show, compared with tradi- tionally two-point control, a win of about ten percent and better behaviour for short term weather change, which is very important for real applications.

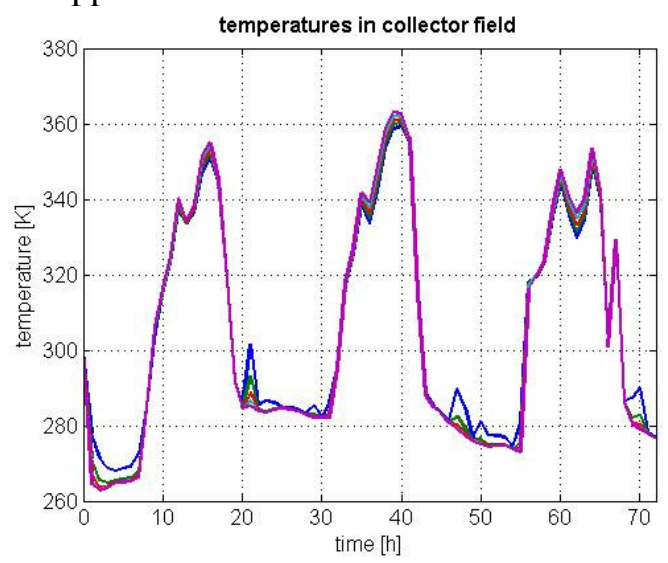

Fig. 6: Temperature of different collector areas
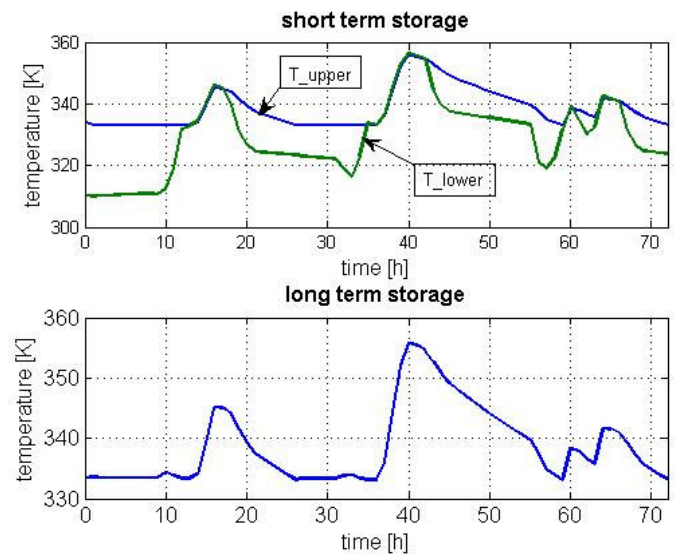

Fig. 7: Storage temperature courses
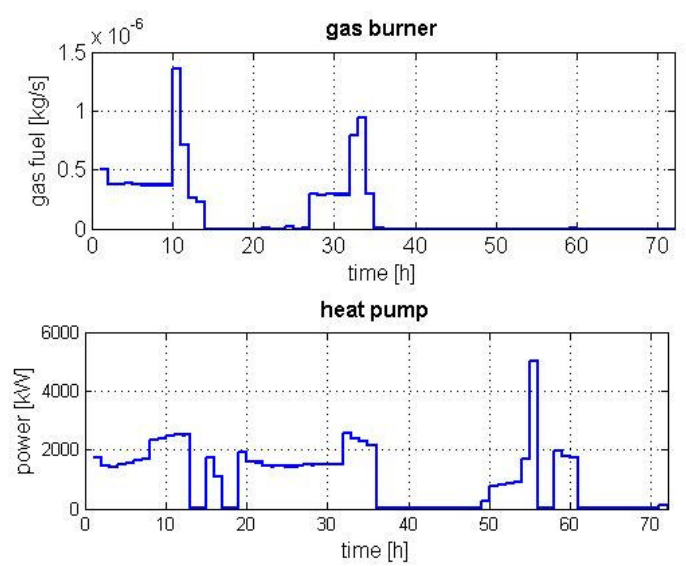

Fig. 8: Optimal courses for burner and heat pump 

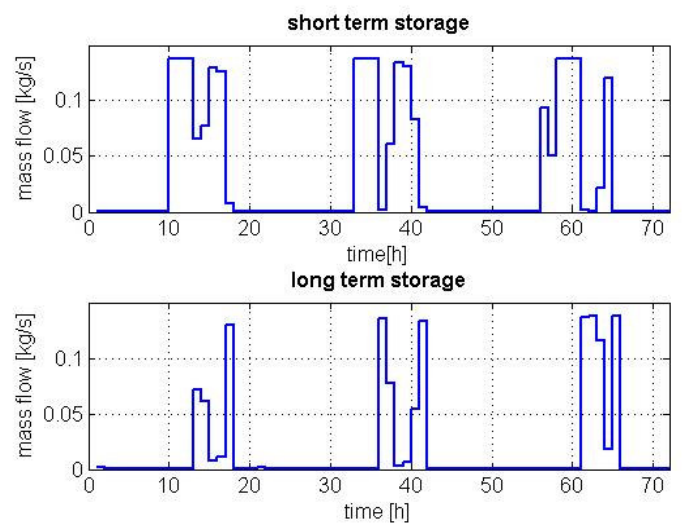

Fig. 9: Optimal loading courses

\section{Model predictive control (MPC) by HQP and Simu- link s-function interface}

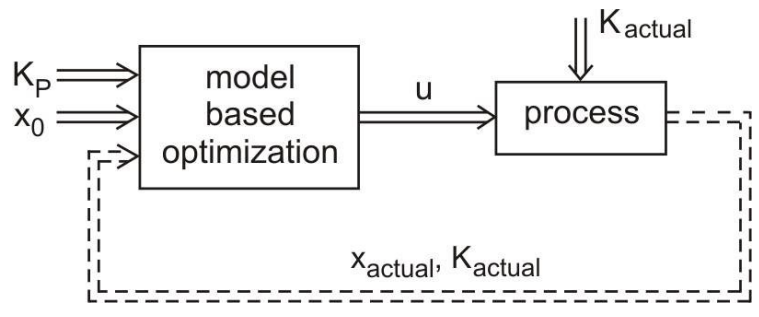

Fig. 10: Model predictive control scheme

For the optimization with MPC-technique [19] a simple plant model with one storage was used. Fig. 11 shows this plant with the following data: - Collector area: $5 \mathrm{~m}^{2}$

- short term storage with a stand by layer of 1351

and a rest part of 1651 , i.e. together 3001 of content.

- gas burner: 10KW.

In Fig. 10 the variables have the following meaning: $x_{0}=x(0)$, initial state, used for optimization, $x_{\text {actual }}$ are the actual start values of $x$ after some time steps, $\mathrm{K}_{\mathrm{P}}$ are forcasted climate data for starting the optimization with $\mathrm{x}_{0}, \mathrm{~K}_{\text {actual }}$ are the actual climate values after some time steps used also as starting values for optimization. As usual the MPC (model predictive control) is based on repetitive optimization, i.e. the control loop is only closed within discrete time steps to include actual data from the different sources (states, forecasts, measured data) for prediction of new optimized values (control and parameter).

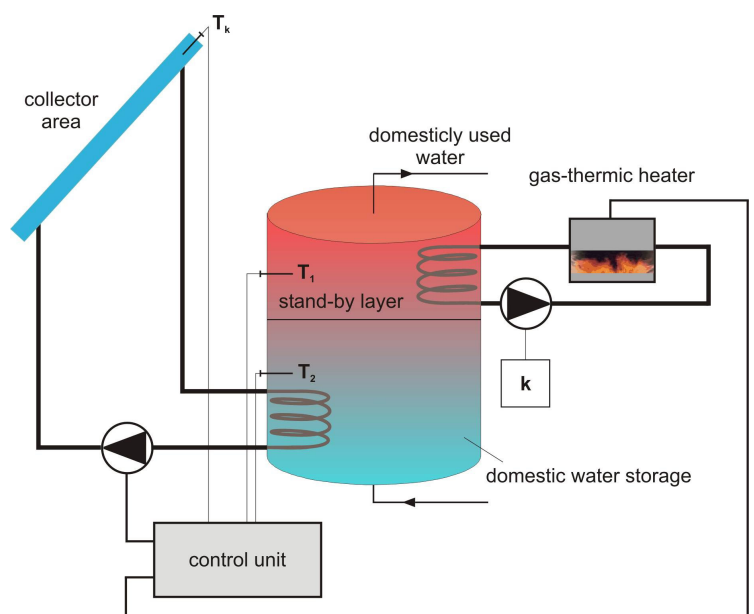

Fig. 11: One storage heating system

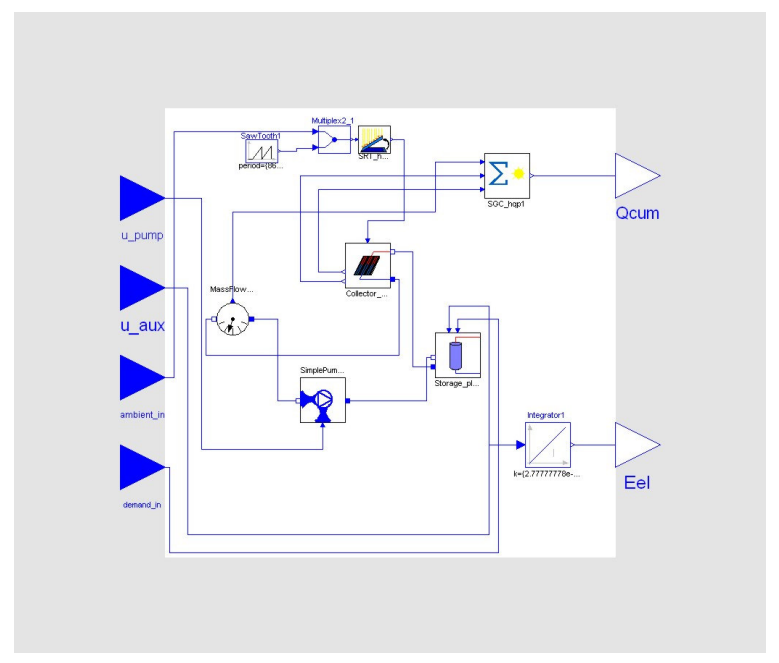

Fig. 12: Dymola/Modelica model from one storage heating system

For dynamic optimization using the Dymola/Modelica model with on storage the following criteria has to be maximized:

$$
I(u)=\int_{t_{0}}^{t_{f}} Q_{\text {cum }}(t) d t
$$

By means of this criterion only the solar energy was maximized this automatically implies the minimization of the fossil energy. The index "cum" stands again for cumulated solar energy. The horizon for the optimization in this example was three hours and the control was applied over a time horizon of two hours. Then the optimization cycles were repeated. In Fig. 14 the results of the MPC are shown.

The advantage of the method is the reaction to altered data from weather or the plant in comparison to the offline optimization. Especially, 
Fig.13 shows the temperatures of the stand-by layer. Through reaction of the altered weather data with MPC-technique the limit can be met.
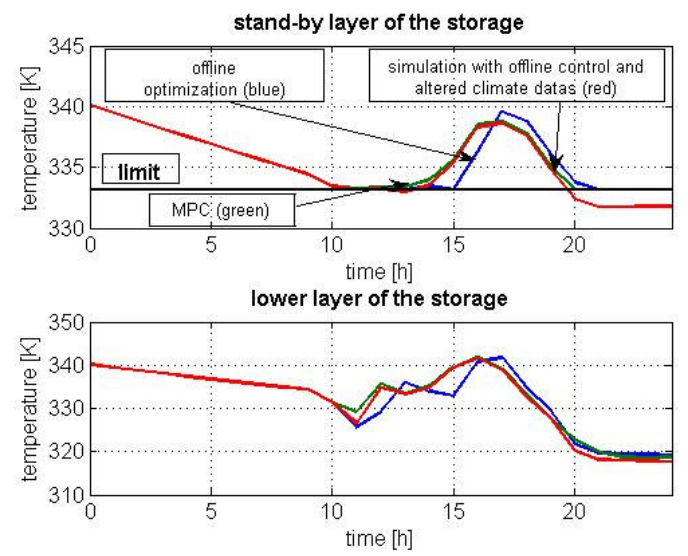

Fig. 13: Storage temperature courses
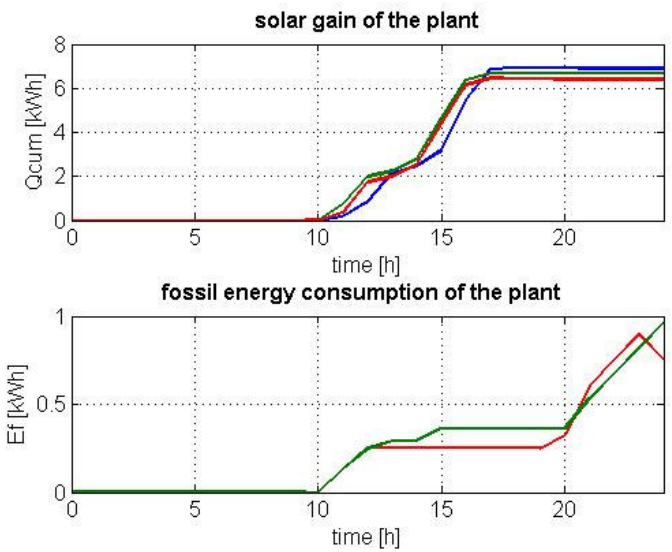

Fig. 14: Result courses

\section{Discrete dynamic pro- gramming (DDP) by Mat- lab coupled with Dymola models via Simulink S- function interface}

DDP [20] was applied to the same one storage heating system how in Fig. 11 shown in.

The problem with this possibility is that the plant should not have too many states und control parameters because the numbers of variables increase exponentially. The problem formulation of the DDP is:

System description:

$\mathbf{x}(k+1)=\mathbf{f}[\mathbf{x}(k), \mathbf{u}(k), k], \quad k=0, \ldots, K-1$

Criterion with constrains:
$I_{k}=\vartheta[\mathbf{x}(K)]+\sum_{k=0}^{K-1} \boldsymbol{\Phi}[\mathbf{x}(k), \mathbf{u}(k), k], K$ fixed

$\mathbf{g}[\mathbf{x}(K)]=0$ (final states constraints)

$\mathbf{f}[\mathbf{x}(k), \mathbf{u}(k), k]=0, \quad k=0, \ldots K-1$ (equality constraints)

$\mathbf{h}[\mathbf{x}(k), \mathbf{u}(k), k] \leq 0, \quad k=0, \ldots, K-1$ (inequality constraints)

The calculation algorithm of the DDP [18] is divided into three parts:

1. Discretization of the considered continuous problem

2. Backward calculation - one stage minimization to calculate optimal transitions of the states (optimal control law)

3. Forward calculation - investigation of the optimal states trajectories and the control parameter courses from the optimal control law.

In the following figures a comparison between HQP and DDP should be shown. The aim of the transformation from HQP to DDP is the insertion to build a hierarchical controller for the heat supply system for buildings on the basis of an embedded microcontroller system. Fig. 15 shows the temperature in stand-by layer of the storage and the collector field temperature. The temperature in the lower layer of the storage is similar to the collector field temperature. The differences of courses are often problems of the discretization intervals of the:

- state with $\Delta \mathbf{x}$ and the

- control parameters with $\Delta \mathbf{u}$

between DDP and HQP.

In case of DDP the discretization is bigger than in case of HQP because of a strong increase of the CPU-time.
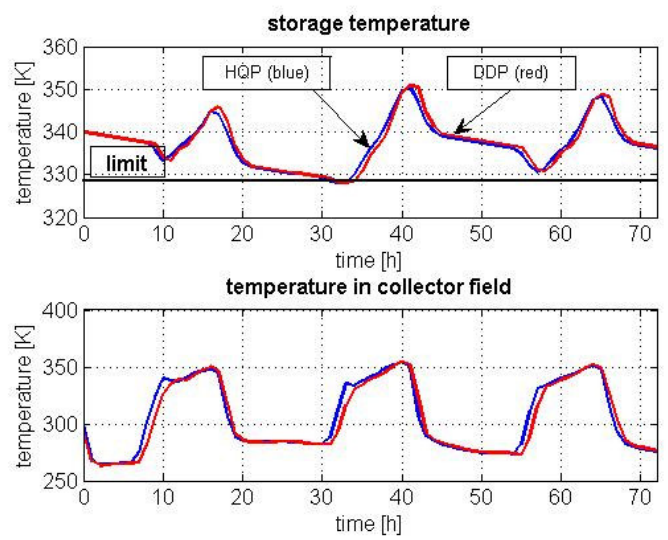

Fig. 15: Storage temperature courses 

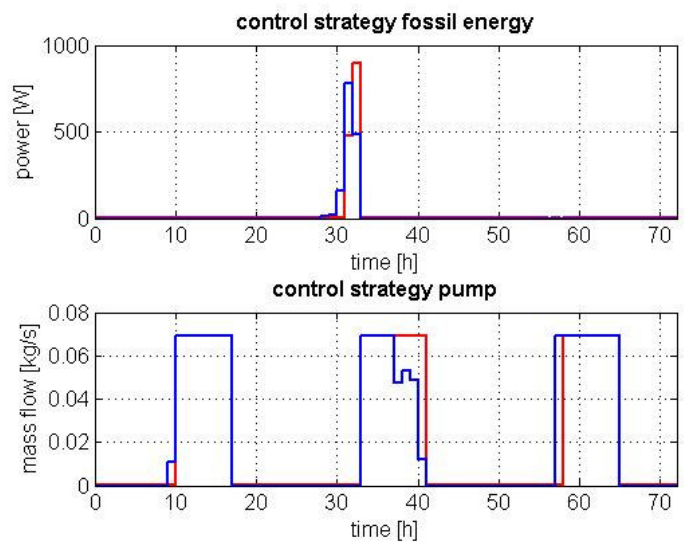

Fig. 16: Storage temperature courses
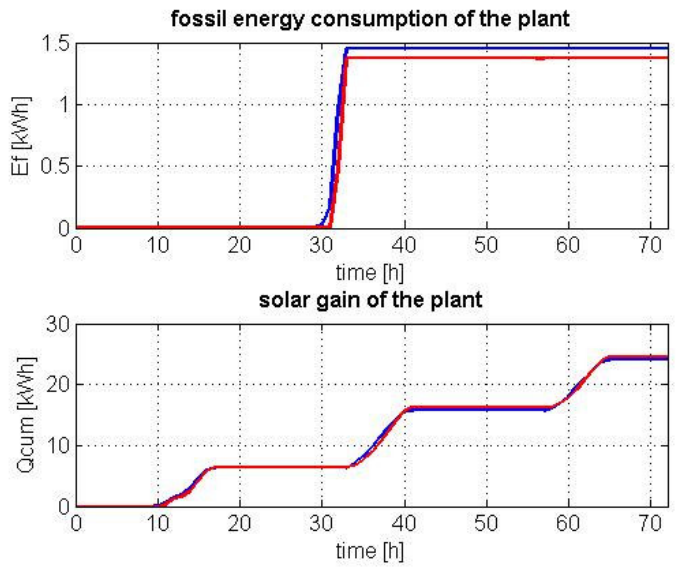

Fig. 17: Storage temperature courses

\section{Conclusion}

As a result of this article can be said that dynamic optimization from heating supply plants with Dymola/Modelica models is advantageous. The application of different optimization techniques shows the universal character of the Dymola/Modelica models. Especially the graphical programming of the plant model is of great value and it makes a relatively fast investigation of control trajectories.

\section{References}

[1] V. Quaschning, (1999), Regenerative Energiesysteme, 2. Auflage, Carl Hanser Verlag

[2] Duffie and Beckmann, (1991), Solar Engineering of Thermal Processes

[3] H. P. Garg, S.C. Mulick and A.K. Bhargava, (1985) Solar Thermal Engergy Storage, D.Reidel Publishing Company

[4] Dymola User's Manual, (2002), Dynamsin AB Lund

[5] J. Kahler, (2002), Entwicklung einer Gebäudekomponentenbibliothek für kontrolliert- belüftete und -entlüftete Niedrigenergiehäuser, Diplomarbeit TU Ilmenau, Inst. für Automatisierungs- und Systemtechnik

[6] M. Kisser, (2002), Entwicklung einer Prognoseverfahrensbibliothek fuer Klimadaten in Dymola/Modelica, Diplomarbeit TU Ilmenau, Inst. für Automatisierungs- und Systemtechnik [7] W. Feist, (1994), Thermische Gebäudesimulation: kritische Prüfung unterschiedlicher Modellierungsansätze

[8] C. Nytsch-Geusen , (2001), Berechnung und Verbesserung der Energieeffizienz von Gebäuden und ihren energietechnischen Anlagen in einer objekt-orientierten Simulationsumgebung, Dissertation, TU Berlin

[9] VDI Richtlinie 6020, (2001), Anforderungen an Rechenverfahren zur Gebäude und Anlagensimulation

[10] F. Felgner et al., (2002), Simulation of thermal building behaviour in Modelica, Proceedings of the $2^{\text {nd }}$ International Modelica Conference

[11] Solar-Institut Juelich, (1999), CARNOT Blockset Version 1.0 User manual

[12] Dr. Valentin EnergieSoftware $\mathrm{GmbH}$, (1999), T-Sol 2.0 User manual

[13] Franke, R. (1998): Integrierte dynamische Modellierung und Optimierung von Systemen mit saisonaler Wärmespeicherung;

Fortschritts-Berichte VDI, Reihe 6, Nr. 394

[14] MODELICA: Modeling of Complec Physical Systems. Modelica-Homepage. http://www.modelica.org

[15] HQP: a solver for sparse nonlinear optimization. Omuses/HQP-Homepage.

http://hqp.sourceforge.net

[16] Ch. Hoffmann, J. Kahler, Puta, H.(2003): Object-oriented simulation of energy supply systems on the basis of renewable energy. In Proceedings of the 3rd International Modelica conference, pp. 189-196, November 3-4, Linköping, Sweden.

[17] Liu,B.Y.H. and Jordan, R.C.(1960): The interrelationship and characteristic distribution of direct, diffuse and total solar radiation,

Solar Energy 4

[18] M. Papageorgiou, Optimierung, 2. Auflage, Oldenbourg Verlag

[19] S. Martin, (2005), Optimierte Waermeversorgung von Gebaeuden, Diplomarbeit TU Ilmenau, Inst. für Automatisierungs- und Systemtechnik

[20] T. Flemming, (2005), Optimierte Steuerung von Energieversorgungsanlagen mit Hilfe 
der Diskreten Dynamischen Programmierung, Diplomarbeit TU Ilmenau, Inst. für Automatisierungs- und Systemtechnik

[21] Matlab: Matrix laboratory. Mathworks-

Homepage.

http://www.mathworks.com/ 